\title{
Application and Development of the Power System Dispatching Automation Technology
}

\author{
Zhizhou Chen \\ Jinzhou Power Supply Branch, State Grid Liaoning \\ Electric Power Supply Co. Ltd \\ Jinzhou, china \\ Czz1980@163.com
}

\author{
Baozhong Gan \\ Jinzhou Power Supply Branch, State Grid Liaoning \\ Electric Power Supply Co. Ltd \\ Jinzhou, china \\ Gbz1556@163.com
}

\begin{abstract}
At present, China is at a critical stage of socialist modernization and further development of the social economy, making life, learning, and the production of electrical energy demand continues to increase, the quality and security of supply requirements more stringent, while dispatching automation is power system automation of the main components of the power system is currently the fastest growing technology, through electricity production, transmission, configuration, maintenance, consumption, management of the entire process. Therefore, this article from the analysis of the electric power system dispatching automation technology features start with the basic functions of the specific application of power system dispatching automation technology and market prospects are analyzed, in order to increase the intensity of the power system dispatch application automation technology and research efforts provide references.
\end{abstract}

Keywords- power systems; scheduling automation; application; development

\section{INTRODUCTION}

With the rapid development of China's economy, industrial electricity consumption and electricity consumption increases people's lives, which for power quality, reliability, security and stability as well as new requirements[1-3]. In recent years, the gradual increase in the size of the power system and showing the differences regionalization, different regions supply capacity, power consumption power is also different. Differences in this series requires the power system to achieve full and reliable scheduling, in order to avoid large-scale blackouts and power generation energy surplus, the limited power resources for maximum benefit. The scheduling of the power system in order to improve efficiency, automation is one of the most effective means[4-6].

Power is the power system dispatching automation system is currently one of the fastest developing technology throughout electricity production, transmission, configuration, maintenance, consumption, management of the entire process, is a collection of network technology, computer communications technology, database technology, objectoriented technology, software technology and other scientific and technological achievements of complex technology, its precise, fast and convenient advantage plays an important role in the system of applications, including power generation, transmission, substation, distribution, and electrical equipment and control, protection and communication equipment, etc. section, is to ensure energy security of power supply reliability Yao, the core means economy. Therefore, the power system as a staff member must advance with the times, to learn and master the advanced power system dispatching automation technology, thus ensuring the reliability of the system, to improve work efficiency[7].

\section{CONSTITUTION OF POWER DISPATCH SYSTEM}

Dispatching automation system, its basic structure, including control centers, master system, station terminals (RTU) and information channel four parts. Depending on the completion of different, this system can be divided for information collection and execution subsystem, information transmission subsystem, information processing subsystem and human contact subsystems. Including: data acquisition and control (SCADA), automatic generation control (AGC), economic dispatch operation (EDC), the grid static security analysis (SA) and dispatcher training simulator (DTS), including energy management system[8]. The main feature is the power grid dispatching automation production process realtime data acquisition and monitoring the safe operation of the power grid analysis, power system state estimation, power load prediction, automatic generation control (provincial grid above) automatic economic dispatch (provincial grid above) and meet the needs of the electricity market and other operations. Equipment county scale grid control centers are generally smaller than the regional power grid scheduling, and workstations, servers generally used in industrial or general commercial PC. Regional power grid scheduling means for scheduling the city grid, scheduling functions and scheduling scope than the large district and provincial power grid is much smaller, regional power plant dispatch does not control the main substation and distribution for all levels within the grid network for real-time monitoring to ensure safe and reliable power supply. National Grid scheduling and dispatching large area power grid control center is equipped with computer equipment than the size of the provincial power grid control centers of large, high-capacity servers and network equipment, application software functionality also makes a difference[9].

Power system substation and transmission and distribution lines and power plants is to contact the user's primary link. Substation automation is intended to replace manual 
monitoring and phone manual operations, improve work efficiency, expand the substation monitoring capabilities, improve the safe operation of the substation level. Substation Automation is the content of the station to run a full range of electrical equipment monitoring and effective control, which features a full computerized device to replace a variety of conventional electromagnetic equipment; secondary equipment digitization, networking, integration, maximize the use of computer cable or fiber optic cable instead of the power signal; achieve operational monitoring of the computer screen; operational management, automated records. In addition to meeting the substation substation automation tasks outside run operation but also as an integral SCADA important part of the grid is an important part of the modernization of electricity production.

Power plant distributed control system (DCS) is generally hierarchical distributed architecture, the process control unit (PCU), run workstation (OS), engineering workstations (ES) and redundant high-speed data communications network (Ethernet) components. Process control unit (PCU) by a redundant configuration of the master module (MCU) and smart I/O module components. MCU module via redundant I/O bus and intelligent $\mathrm{I} / \mathrm{O}$ module communication. PCU directly to the production process, accept on-site transmitter, thermocouple, RTD, electrical quantities, switch, pulses and other signals for operating parameters after the operation processing, real-time display and print as well as the state of the output signal of the device directly driven execution agency to complete the production process monitoring, control and interlock protection. Run workstation (OS) and engineering workstation (ES) provides a human-machine interface. PCU run workstation receives incoming information and give instructions to PCU, provide a means to monitor and control the plant operation personnel to run the operation. Engineers workstations and modify system configuration settings, system diagnostics and maintenance tools for maintenance engineers.

About the system dispatching automation technology consists of three parts, namely: dispatch terminal equipment and plant stand side channel. Of course, depending on the charge of different functions can be divided into its subsystem is responsible for information transmission, is responsible for the information collection subsystem, responsible for information processing subsystem and subsystem responsible for human-computer links.

1 , the main function is responsible for information collection subsystem that real-time information system is responsible for co-ordinating the various power plant operating conditions, should also be responsible for receiving instructions issued by the superior dispatch center operations.

2 , the main function of the subsystem is responsible for the transmission of information is information gathering and execution issued by the sub-control center, which acts as a bridge to exchange, core course, the number of communication aimed at achieving the master station side and front-end connected.

3 , responsible for information processing subsystem is the core of the entire automated scheduling technology, which is based on a computer system as the main component. The system includes a number of direct-to-grid scheduling needs of the application software, the purpose of being able to do some work on a variety of processing and analyzing information has been collected, and ultimately to the power equipment automation control.

Power system dispatching automation technology requires four basic characteristics: (1) power system dispatching automation technology need to be able to accurately and timely collection, processing, testing the actual information throughout all grid components, partial and total power system operation. (2) economic indicators in accordance with the technical requirements of the specific operation of the power grid as well as all the components of the system, and provide a scientific basis for the data to make the correct scheduling staff scheduling and control decisions. (3) able to achieve coordinated handling of the entire grid system, ensure that the entire power system operation security, stability and economy, and to provide users with high-quality power supply service. (4) power system automation technology can provide efficient power grid, reducing the incidence of accidents electricity system, while also extending the life of machinery and equipment to ensure a stable and safe operation of the entire power system, especially to prevent the power system The large-scale power outages or system crashes and other incidents of chain-type appearance.

\section{APPLICATION OF POWER SYSTEM DisPATCHING AUTOMATION TECHNOLOGY}

Currently dispatching automation technology has been widely used in the power system and get good results, at this stage the main achievement of the features and technologies, including the detection and control, calculation and analysis, economic dispatch, in addition to its treatment in the accident, planning control, remote training and technical personnel and so have many applications.

\section{(A) Monitoring and Control}

Based on real-time information gathering technology and implementation of monitoring technology, through the process of power system operation and monitoring information to complete the acquisition, processing, display, logo, printing, providing real-time data base for the automatic generation, economic dispatch, high-level security analysis capabilities. In monitoring the system while achieving real-time feedback, and anomalies and failures of independent judgment and warning. By way of the man-machine contact, remote operation of circuit breakers and other components for local control functions and full control.

\section{(B) Calculation and analysis}

With real-time data is based on technical data through the system summary and processing, operation of the various subsystems, components, circuit modules are calculated on the false accident simulation runs, the results of operations and to achieve self-analysis results back to a single equipment failure is simulated object, abnormal situations and accidents that may occur forecasting and warning, to provide a theoretical basis for scheduling and control systems. 


\section{(C) economic dispatch}

Scheduling automation technology plays an important role in the control of power generation, transmission cost aspects of power system. System power balance constraints and consider the impact of the loss on the network, to meet the power quality and system security, based on fuel costs by controlling the power generation methods such as cost control, the whole system at the lowest cost to the principle of active load scheduling automation technology assigned to each controllable generators, static process to achieve economic dispatch.

\section{Specific applications are as follows:}

(1) Siemens SPECTRUM system. This system was developed by Siemens in basis points SPAC 32bit SUM workstation hardware and other equipment on the concepts introduced software bus, etc., between the server and the server and all internal processes and data information between utilities and standardized R \& D out. Adopt a distributed objectoriented components and other technologies have been widely used in urban power companies, distribution companies and industrial users.

(2) CAE systems and SPIDER system. CAE system which uses a 64bit of ALPHA workstation, EMS hardware technology platform dual Ethernet architecture, client-server architecture, it is possible to reduce the network data stream. The SPIDER system has a dual-bit processing capabilities of remote sensing, making the state more stable signal, which uses a distributed database and a modular structure, in accordance with the actual requirements of the user to configure the system.

(3) SD-6000 and OPEN-2000 energy management system. SD-6000 system is at the southern end of the Swiss company in Nanjing and Zibo Electric Power Bureau jointly developed, it has the ability to manage the effect of the open, the use of ultra-large-scale power system dispatch projection screen, meteorological chart and scheduling phone automatically Dialup and other advanced technologies. OPEN-2000, such as an open system with a variety of features and distributed for the provincial tone, tune in to the network as well as medium-sized. In addition, OPEN-2000 system also has a perfect performance, using a wide range of high stability, easy maintenance and a variety of features.

(4) CC-2000 dispatching automation system. The system is composed of China's Electric Power Research Institute, Northern Power Company, Beijing Branch East companies and research and development from Tsinghua University, using object-oriented technology and distributed architecture design, as well as in the use of event-driven package ideological basis, Application software provides transparent connection port. In addition, the system uses the collected information in real-time data, process the data, and in accordance with the specific function to be distributed on different workstations ALPHA server node was distributed systems. So a node failure does not affect the overall stability of the system. In addition, CC-2000 dispatching automation system in the country tune, North China Power Grid Dispatching and Communication Center, the Zhuhai Power Dispatching and Communication Center, the
Guizhou Power Dispatching and Communication Center and the Northeast Power Grid Dispatching and Communication Center has been so successfully applied for China's electric power system security, economy and stable operation to provide technical support.

\section{DEVELOPMENT OF POWER SYSTEM DISPATCHING AUTOMATION TECHNOLOGY}

Power system dispatching automation system is to follow the principle of the law of development, to meet the application requirements need to comply with the direction of the development of science and technology.

\section{(A) the development of principles}

With the rapid development of the information technology, automation technology closely integrated scheduling and technological progress and constantly optimize the sound toward standardization, comprehensive, intelligent, digital, network, market-oriented direction. Throughout the development of the power system dispatching automation system, which can be summed up with common characteristics, while also dispatching automation technology development is bound to follow the principle of the development needs of the system:

First, the hardware. Hardware and gradually expand the application coverage from special-targeted initially strong, and gradually realize the integration common to general-direction.

Second, the structure. Combines integrative graphic model library and other relevant technologies, dispatching automation system gradually shift from a centralized to a distributed. Third, the function. Systems engineering from the original basis of the monitoring, collection, like the full control of the direction of development.

\section{(B) development needs}

With the popularity of automated scheduling application system, which at this stage in the application of the existing problems and needs gradually, and the development of appropriate technology must be consistent with the system application needs. The main problem at this stage in: an electricity market for power system requirements increase; two, a national network of system security challenges; three, there are loopholes in security and defense systems cause abnormal supply, power supply accident; four, the national security system on the power system defense capability requirements. Based on the above issues, scheduling automation systems need to achieve new development needs: an integrated, realtime, controllability, uniformity, stability, large capacity.

\section{(C) the development direction}

Scheduling automation technology development should be based on international technological achievements, to conform to the principles of the system for the direction of development in order to solve the existing problems as a prerequisite to meet the needs for the purpose of system applications.

First, the integrated automation. Local control of the region to solve some existing problems and improve the scheduling database by establishing integrated management capacity, 
monitoring feedback, computational analysis, anomaly prediction, incident handling, scheduling, control, coordinate planning system-wide integrated automation. Second, digitized. Digital substation and grid development, combined with IT power system of digital information, digital management, digital communication, decision-making digitized, thus optimizing system efficiency and operational quality. Third, intelligent. To establish a network protection and emergency control integrated system wide synchronization information for the purpose of using data integration technology, the system runs the information timely and effective access, maximize overall optimal intelligent scheduling, operation and management. Fourth, the market. The electricity market is a challenge to the power system, solve the problem of network capacity, power plug, load and other unpredictable issues imperative need existing systems into the market factors and operating systems combined. Fifth, standardization. With the enhanced system applications, the technology will also towards the systematic, standardized direction. On the one hand, attaches great importance to the existing technical standards and in-depth research to meet the current standards as a precondition; on the other hand, combined with international technology development processes and systems need to create conducive to promoting technical quality and applicability of the new standards.

\section{CONCLUSION}

Power system dispatching automation technology is the protection of the entire power system security, stability and the effective operation of the core technology, so its application and development plays an important role also has a high demand, especially in the application of new technologies and new theories constantly being updated so that some of the concepts and correction, blurring the traditional boundaries of technology, a variety of original seemingly associated technologies will penetrate into each other and that promote the continuous development and changes in power automation systems. In actual operation, and work, and the problem of power system applications with more particularity and uncontrollable factors, the need to design, technicians, operators establish a solid foundation of theory and practice, to be sufficient to deal with the optimization of the actual situation, better play the role of technology to achieve system effects.

\section{REFERENCES}

[1] Tan. S. W, "Analysis and research of real-time communication current situation in power dispatch automation for China south power grid ,' Power System Protection and Control, vol. 38, pp. 109-114,2010.

[2] Zhang. R, Du. Y, Liu. Y, "New challenges to power system planning and operation if smart development in china ," In: International Conference on Power System Technology, Hongzhou,China, pp. 1 8,2010 .

[3] Pourbeik. P, Kundur P S, Taylor C W, “ The Anatomy of a Power Grid Blackout," IEEE Power \& Energy Magazineno, pp. 22-29,2006.

[4] Sergey. V B, Roni. P, Gerald. P, Eugene. S H, Shlomo. H, "Catastrophic cascade of failures in interdependent networks ," Nature, vol. 464, pp. 1025-1028,2010.

[5] Laprie. J C, Kanoun. K, Kaâniche. M, “ Modelling Interdependencies Between the Electricity and Information Infrastructures ," In: Saglietti, F, Oster, N. (eds.) SAFECOMP 2007. LNCS, vol. 4680, pp. 54 67,2007 .

[6] Deepa. K, Xianyong. F, Shan. L, Takis. Z, Karen. L B, “ Towards a Framework for Cyber Attack Impact Analysis of the Electric Smart Grid ," In: 2010 First IEEE International Conference on Communications, pp. 244-249,2010.

[7] Xiao. X, Yang. Y, Zhai. G, “ The Design of a Personalized Information Service System Based in Internet. Computer Engineering and Science, vol. 24, pp. 59-62,2002.

[8] Li. S, Yu. G, “ Electric Grid Dispatching Database Modelling ," The Academic Journal of Shandong Junior College, vol. 13, pp. 54-60,2010.

[9] Kim. D. H, Song. J. Y, Lee. S. H, Cha. S. K, “ Development and evaluation of Zigbee node module for USN ," Int. J. Precis. Eng. Manuf. 10(5), pp. 53-57,2009. 